\title{
it-sa Nürnberg
}

Vom 7. bis 9. Oktober 2014 dreht sich auf der it-sa wieder alles um IT-Sicherheit. Es gibt Gelegenheit zum Austausch mit den führenden Branchenexperten und dazu, sich über die neuesten Produkte und Dienstleistungen zu informieren. Neben den Top-Themen Cloud Security, Mobile Security, Verschlüsselung, IT-Compliance und Biometrie finden auch Basics wie Netzwerksicherheit, Virenschutz oder IT-Grundschutz eine breite Präsentationsfläche.

\section{Erfolg am neuen Ort}

Die it-sa hat ihren Ursprung im Security-Forum der Systems München. Seit 2009 wird sie als eigenständige Messe im Messezentrum Nürnberg veranstaltet und die außerordentlichen Wachstumsraten bestätigen die Notwendigkeit, dem für alle Unternehmen mittlerweile existenziellen Thema IT-Sicherheit eine eigene, alljährliche Plattform zu geben. Wenige Jahre nach ihrem Start zählt die it-sa zu den bedeutendsten ITSecurity-Messen weltweit. Ein umfassendes Angebotsspektrum und eine Vielzahl an Sonderflächen bieten der Branche die Möglichkeit, sich gezielt über die am heißesten diskutierten IT-Security-Themen auszutauschen.

Der begleitende Congress@it-sa bietet intensive Wissensvermittlung und vertiefte fachliche Diskussionen mit Verbänden, Branchenvereinigungen und Anbietern von IT-SecurityLösungen. Abseits des Messetrubels ein perfekter Rahmen für IT-Sicherheitsbeauftragte, Netzwerkadministratoren und Leiter von Rechenzentren für Know-how aus erster Hand und intensive Dialoge mit Experten.

\section{In Zahlen}

2013 haben über 6900 Fachbesucher sowie Mitarbeiter ausstellender Unternehmen und eine Vielzahl von Medienvertretern die Dialogplattform it-sa genutzt, um sich umfassend rund um das Thema IT-Sicherheit zu informieren und auszutauschen. 358 Unternehmen stellten ihre Produkte und Dienstleistungen vor.

Weitere Informationen finden Sie unter http://www.it-sa.de/

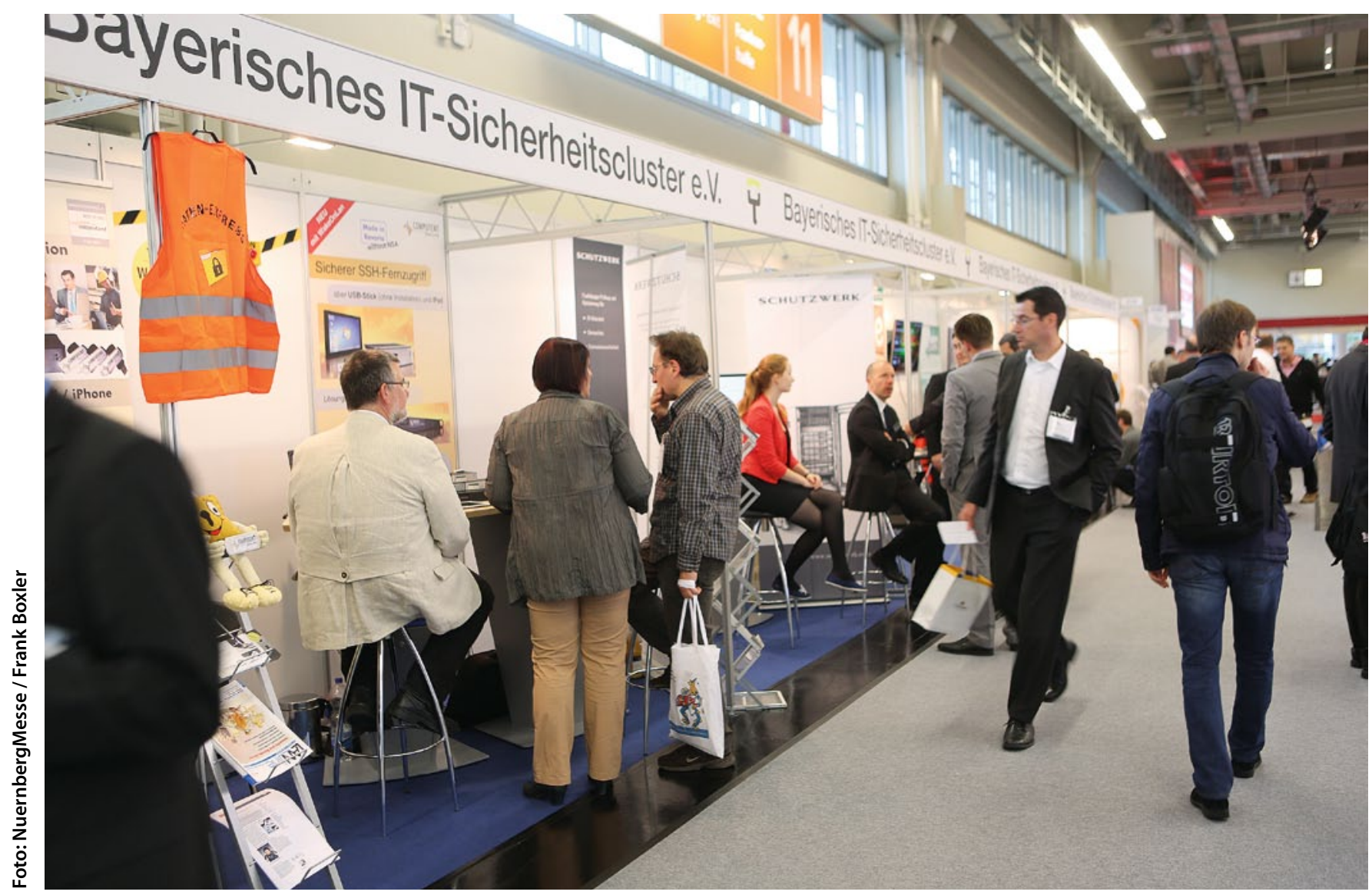

